\title{
Dolor abdominal e hipotensión en paciente con antecedente de trasplantectomía
}

\author{
Caballero Romeu JP, Leivar Tamayo A, Giner Santamaría C, Galiano Baena JF, \\ Pelluch Auladell AM Lobato Encinas JJ.
}

Servicio de Urología Hospital General Universitario de Alicante.

Actas Urol Esp. 2007;31(2):175-176

$P_{t}^{a}$ aciente mujer de 63 años de edad trasplantada en fosa iliaca izquierda en octubre de 2005. Se realizó una anastomosis arterial termino lateral a arteria iliaca externa y una anastomosis venosa termino lateral a vena iliaca izquierda. Durante el postoperatorio, la paciente mantuvo una diuresis escasa con una Creatinina de $5 \mathrm{mg} / \mathrm{dl}$. A los 12 días postrasplante, se intervino por un sangrado en la zona del injerto que no se controló con transfusiones repetidas. Se consiguió una correcta hemostasia, tras dar dos puntos de sutura a nivel de la anastomosis arterial, pero 24 horas después la hemorragia, recidivó por lo que se reintervino. Tras esta intervención, la paciente permaneció estable aunque requirió hemodiálisis. A los 10 días, la paciente mantuvo un sangrado discreto pero continuo y la Eco Doppler puso de manifiesto la falta de flujo vascular renal. Dado el sangrado incoercible y la falta de función del injerto se llevó a cabo una trasplantectomía. La anatomía patológica evidenció un riñón con necrosis de coagulación y necrosis anémicas masivas. La paciente no presentó nuevas complicaciones.

Cinco meses más tarde, la paciente acudió al hospital por dolor abdominal de 5 días de evolución. Durante su estancia en urgencias presentó un cuadro de hipotensión. La analítica de sangre mostró una $\mathrm{Hb}$ de $6 \mathrm{~g} / \mathrm{dl}$. La ecografía abdominal objetivó una colección $14 \mathrm{~cm}$ de diámetro en fosa iliaca izquierda. Con la sospecha clínica de sangrado activo en relación con la trasplantectomía, se solicitó una TAC urgente con contraste puesto que en nuestro medio es más accesible que una arteriografía urgente. La TAC (Figs. 1 y 2) mostró una imagen sugestiva de extravasación de contraste indicativo de sangrado activo a partir de la arteria iliaca externa dentro de una colección de

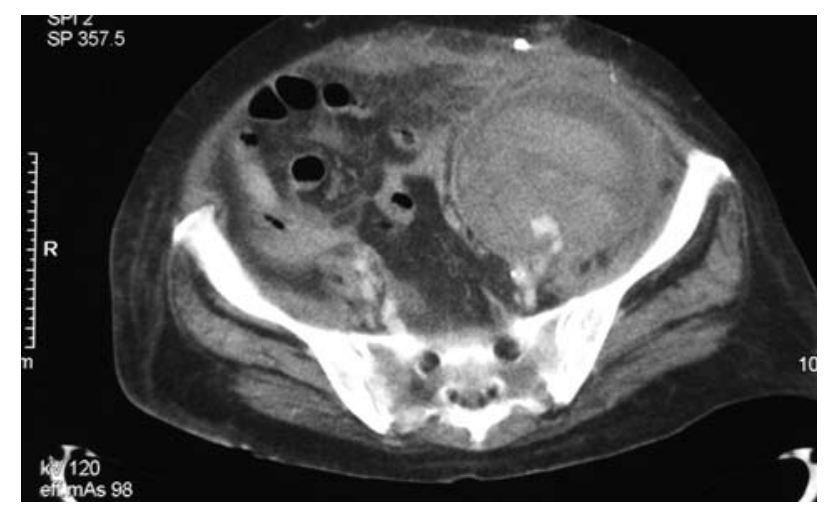

FIGURA 1. TAC abdominal con contraste: Localización del punto de sangrado en la arteria iliaca externa izquierda.

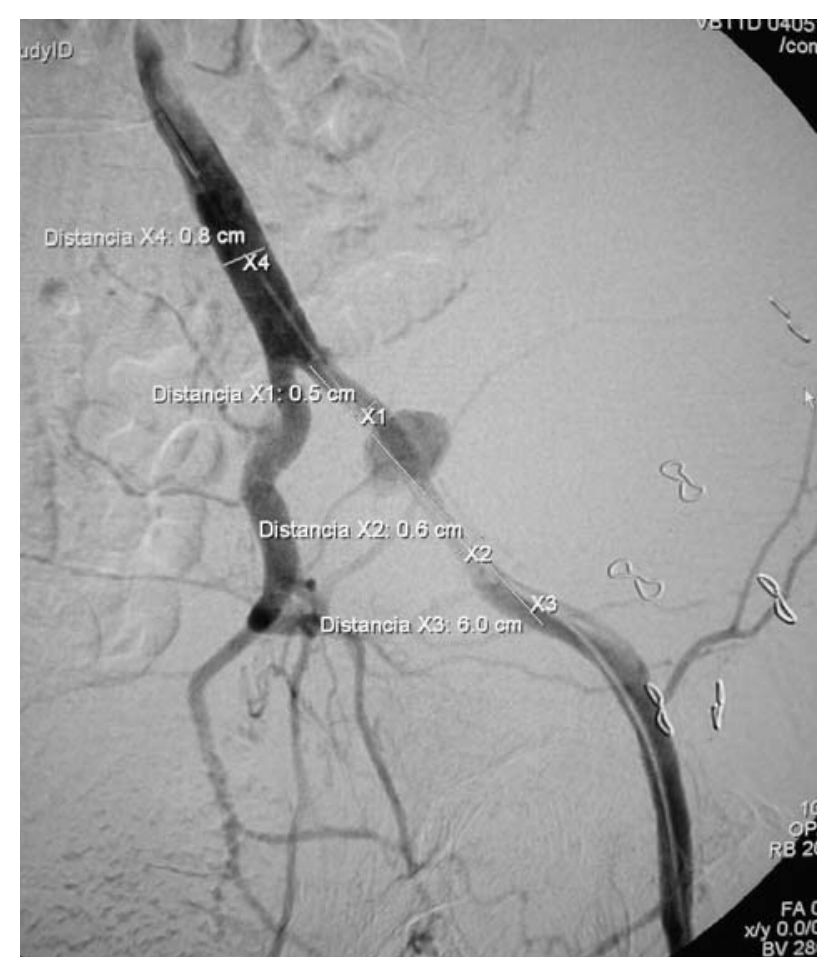

FIGURA 2. Localización de pseudoaneurisma y Medición de la distancia hasta la bifurcación iliaca previa a la colocación de la endoprótesis. 
$16 \times 16 \times 12,5 \mathrm{~cm}$. Nos pusimos en contacto con la Sección de Radiología Intervencionista y por vía femoral se realizó una arteriografía selectiva (Fig. 3) visualizándose un pseudoaneurisma y se

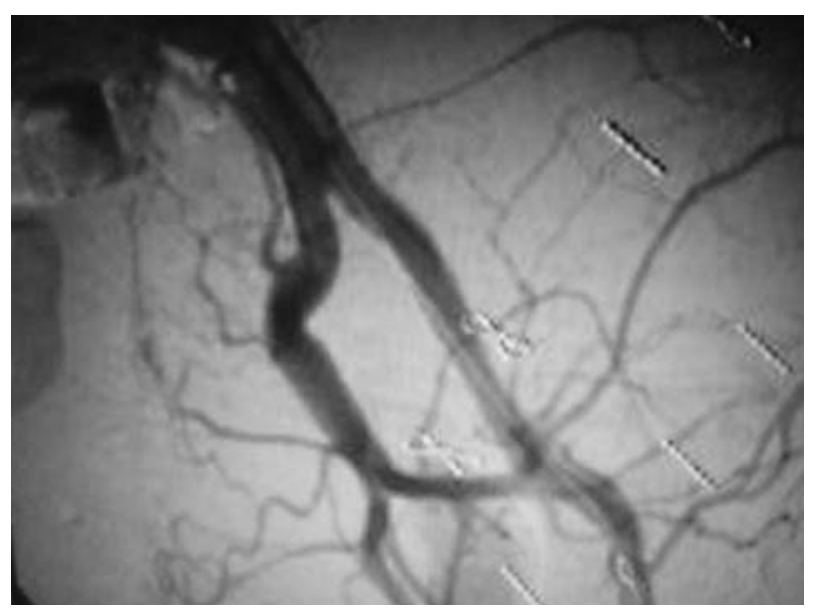

FIGURA 3. Comprobación de la resolución del sangrado tras la colocación de la endoprótesis. identificó la presencia de un punto de sangrado a 2 $\mathrm{cm}$ de la bifurcación iliaca. Se colocó un stent autoexpandible de nitinol con recubrimiento interno de politetrafluoroetileno (PTFE) recubierto "Viabahn". La arteriografia de control demuestra el cese del sangrado. Actualmente la paciente se encuentra bien, en tratamiento sustitutivo con hemodiálisis. El diagnóstico de un sangrado arterial se realiza preferentemente mediante arteriografia. Es poco común que una TAC con contraste permita localizar un punto concreto de sangrado con la precisión con la que se hizo en nuestro caso. Aquí, la arteriografia fue fundamentalmente terapéutica.

Correspondencia autor: Dr. J.P. Caballero Romeu Servicio de Urología. Hospital General Universitario de Alicante. Pintor Baeza, s/n. 03010 Alicante. Tel.: 965938000

E-mail: juanpablocaballero@gmail.com

Información artículo: Imágenes en Urología

Trabajo recibido: mayo 2006

Trabajo aceptado: julio 2006 